Supplement of The Cryosphere, 14, 3935-3958, 2020

https://doi.org/10.5194/tc-14-3935-2020-supplement

(C) Author(s) 2020. This work is distributed under

the Creative Commons Attribution 4.0 License.

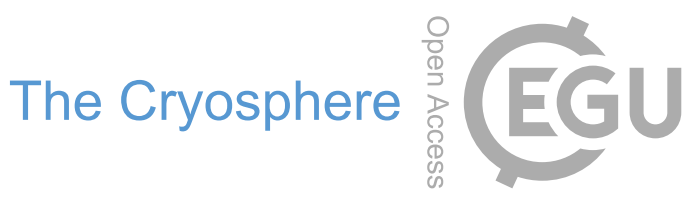

(c) (1)

Supplement of

\title{
GrSMBMIP: intercomparison of the modelled 1980-2012 surface mass balance over the Greenland Ice Sheet
}

Xavier Fettweis et al.

Correspondence to: Xavier Fettweis (xavier.fettweis@uliege.be)

The copyright of individual parts of the supplement might differ from the CC BY 4.0 License. 


\section{Supplementary of GrSMBMIP (Fettweis et al., 2019)}

\begin{tabular}{|c|c|c|c|}
\hline & \multicolumn{3}{|c|}{$\begin{array}{c}\text { PROMICE - GrIS + ice caps } \\
(\# 1683 ;-0.84 \pm 0.61 \mathrm{mWE})\end{array}$} \\
\hline & Bias & RMSE & Correlation \\
\hline BESSI (EBM) & 0.38 & 0.87 & 0.79 \\
\hline BOX13 (RCM) & 0.24 & 0.86 & 0.77 \\
\hline CESM (GCM) & 0.11 & 0.66 & 0.86 \\
\hline dEBM (EBM) & -0.06 & 0.64 & 0.87 \\
\hline HIRHAM (RCM) & 0.13 & 0.58 & 0.90 \\
\hline IMAU-ITM (EBM) & -0.02 & 0.60 & 0.88 \\
\hline MAR (RCM) & 0.10 & 0.49 & 0.93 \\
\hline MPI-ESM (GCM) & -0.06 & 0.76 & 0.81 \\
\hline NHM-SMAP (RCM) & 0.40 & 0.77 & 0.89 \\
\hline PDD1km & & & \\
\hline PDD5km & & & \\
\hline RACMO (RCM) & -0.07 & 0.62 & 0.89 \\
\hline SNOWMODEL (EBM) & -0.30 & 0.67 & 0.89 \\
\hline ENSEMBLE & & & \\
\hline
\end{tabular}

Table S1. Same as Table 3 but by considering all the measurements, from the PROMICE data base, which are on the main ice sheet or on the peripheral ice caps. 


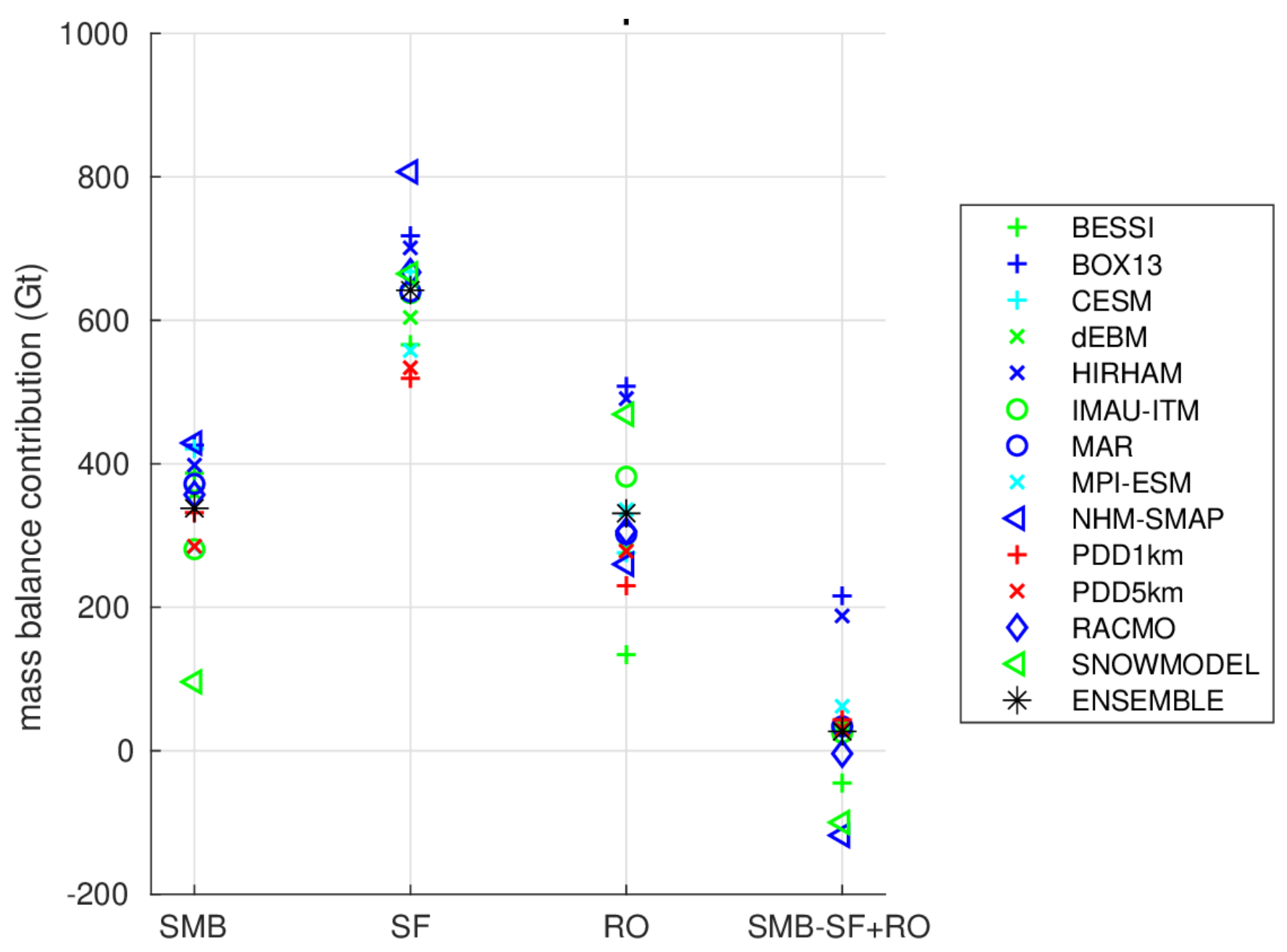

Fig S1: The main mass balance components (as listed in Table2). 


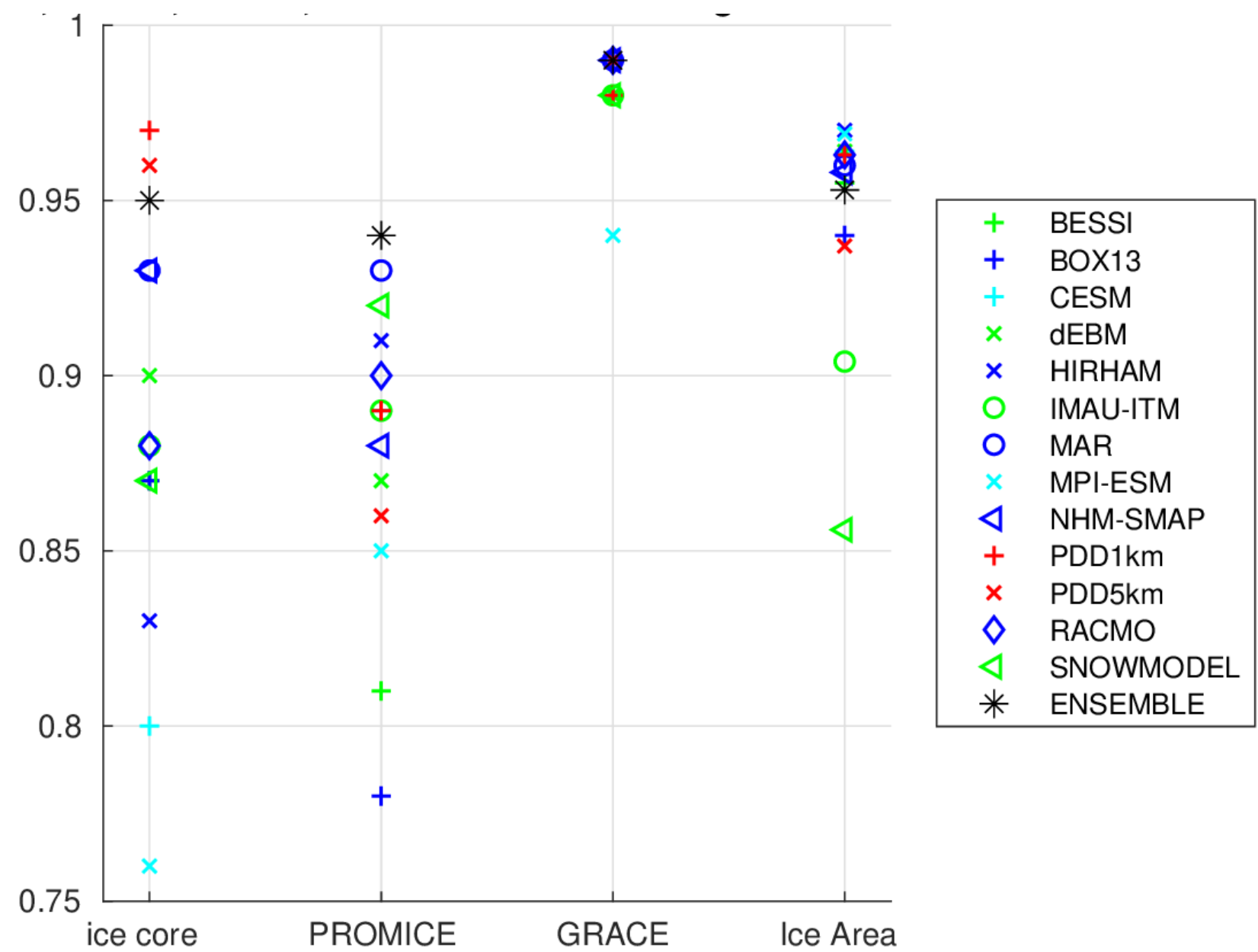

Fig S2: Correlation (listed in Table 1) of each model vs the 4 validation data sets used in GrSMBMIP, distinguishing PDD models (red), EBMs (green), GCMs (cyan) and RCMs (blue) 


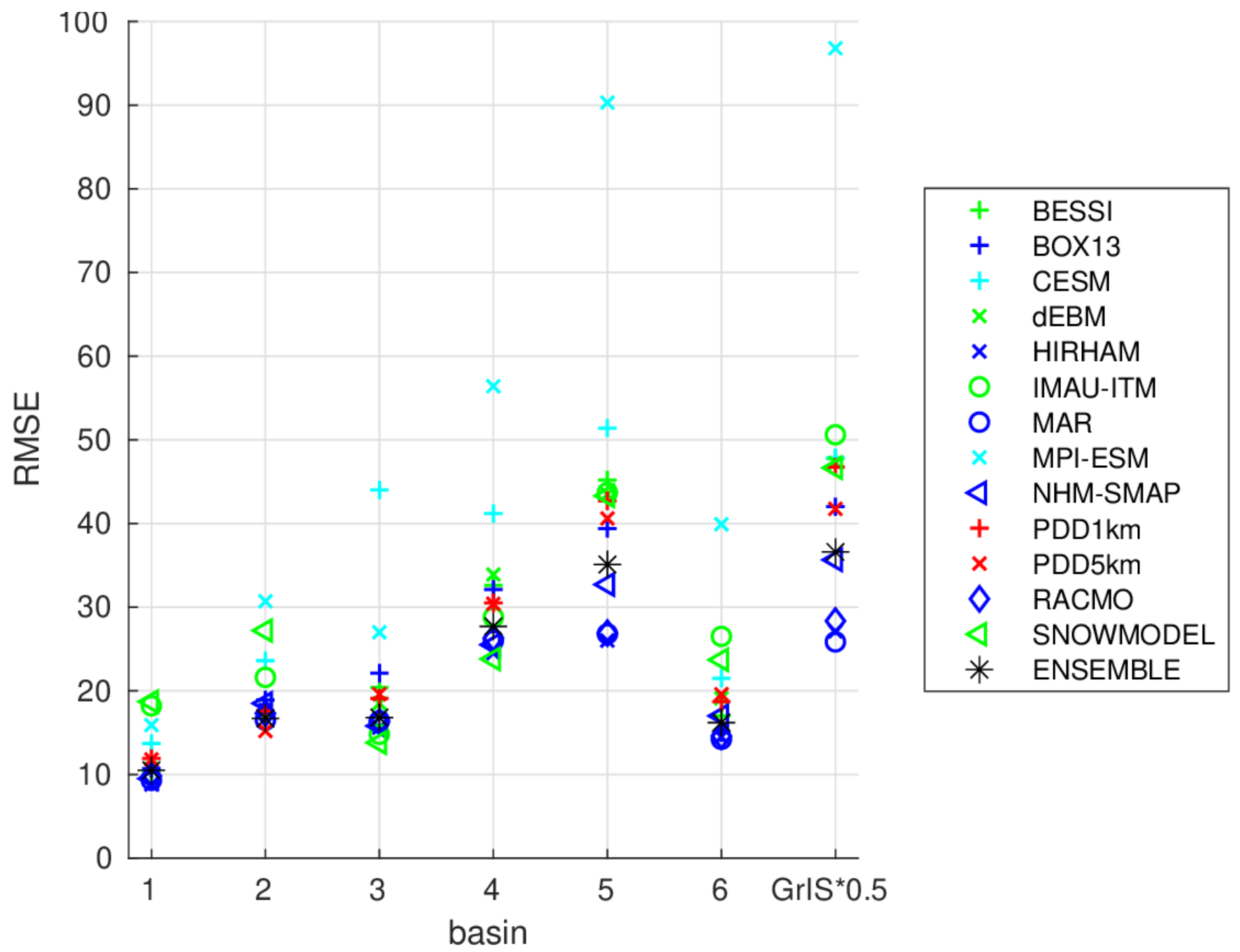

Fig S3: RMSE (listed in Table 2) of each model vs the GRACE based time series. 